\title{
Research Skills Enhancement in Future Mechanical Engineers
}

\author{
doi:10.3991/ijep.v1i1.1590 \\ F. Jorge Lino, Teresa P. Duarte \\ Universidade do Porto, Porto, Portugal
}

\begin{abstract}
Nowadays, the Web is a common tool for students searching information about the subjects taught in the different university courses. Although this is a good tool for the first rapid knowledge, a deeper study is usually demanded.

After many years of teaching a course about ceramic and composite materials in the Integrated Master in Mechanical Engineering of Faculty of Engineering of University of Porto, Portugal, the authors used the Bologna reformulation of the mechanical engineering course to introduce new teaching methodologies based on a project based learning methodology.
\end{abstract}

One of the main innovations is a practical work that comprises the study of a recent ceramic scientific paper, using all the actual available tools, elaboration of a scientific report, work presentation and participation in a debate.

With this innovative teaching method the enrolment of the students was enhanced with a better knowledge about the ceramics subject and the skills related with the CDIO competences.

This paper presents the reasons for this implementation and explains the teaching methodology adopted as well as the changes obtained in the students' final results.

Index Terms-Engineering Education, Mechanical Engineering, Ceramic Materials, Project Based Learning.

\section{INTRODUCTION}

Teaching with success is a very demanding task, especially in present time, where the students have a continuous contact with the powerful tools of internet and media and nothing seems to surprise them. This way, rapid knowledge is obtained at the distance of a simple mouse click, independently of the region of the world where a person is.

Nowadays, when students are admitted in the university, they have already a big control of specific informatics tools, such has typing texts in word processer and making good power point presentations, and many of them are quick at searching for an answer in the World Wide Web. However, when a deeper knowledge about the subjects is required, difficulties start to appear, and essentially when some background about certain scientific principles is demanded, the problems are even bigger [1]. This is the main deficiency that the authors detected on their mechanical engineering students during their classes about ceramic materials.

The Faculty of Engineering of University of Porto (FEUP), Portugal, has the Integrated Master Course in
Mechanical Engineering (MIEM) that obtained the EURACE Accreditation of European Engineering Programs in 2008. This course has a considerable incidence in materials and technological processes. The introduction of these subjects with the detail that is presently taught is related to the type of mechanical engineers' necessities of the region and the country industrial tissue, and the global employment market.

One of the main concerns of the mechanical engineering professors of FEUP is the transmission of the best general competences CDIO (Conceive-DesignImplement-Operate) [2] and scientific knowledge, and also the development of skills that will be very helpful in the future active professional life.

The curricular unit of Materials II [3], of the third year of MIEM, first semester, is divided in two main subjects; i) study of ceramic materials and ii) study of polymers and composites of polymeric matrix. The authors of this work are in charge of teaching the part of ceramic materials, which represents more than one third of the course (10 classes of $2 \mathrm{~h}$ each, in a total of 24 classes). The scientific knowledge is transmitted with the help of practical classes, where videos, experimental work and technical visits to ceramic manufacturing companies are used.

In the past, teaching was performed in the classic way with theoretical and practical classes. In the theoretical classes ( 8 classes of 1 hour for around 130 students at the same time, where it was impossible to have a personalized knowledge about each student), and considering the short number of classes to teach the subject "ceramics", the emphasis was put on clarifying the differences between traditional and technical ceramics. A short introduction to the sintering process and explanation of the main differences between solid state and liquid phase sintering, and relating them with the final mechanical properties of the ceramic products, was also addressed. After this, students had a short introduction to the manufacturing processes and mechanical properties, with special emphasis on toughness and current research that has been conducted to improve these properties, in order to be able to increase the penetration of ceramics in the materials world parts applications (Harmer, Chan and Miller [4] wrote an excellent paper about these challenging opportunities).

In the practical classes ( $2 \mathrm{~h}$ for 25 students, maximum) students had the opportunity to carry on simple experiments, namely press powders, determine densities and respective level of porosity and finally evaluate the effect of sintering on the mechanical resistance of the samples and microstructural changes. 
The final grade was composed by $20 \%$ for the reports of practical classes and the remaining $80 \%$ for the final exam.

In 2006, when the course was approved by Bologna Process, the classes were changed to just practical ones (with 4 works for ceramics and 3 for polymers) with the goal of giving the student a more responsible and proactive attitude, which is characterized by spending much more time at university/home studying the main topics taught in classes. Although the contents of the course remain the same, at the beginning of some classes each subject is briefly presented during $15-20$ minutes maximum. After that, students have to answer the questions of the practical works using class facilities and complementary work done at university/home (the course has 6 ECTS - European Credit Transfer and Accumulation System [5], where 1 ECTS corresponds to $27 \mathrm{~h}$ work).

After 2008, 2 reports for each part: ceramics and polymers, and answers to some handouts to be solved in class or at home are the only responsible items for the final grade obtained. This means that a deeper knowledge has to be obtained about the students from the discussions in all practical classes and continuous contact with the teacher, to obtain a more accurate and fair assessment.

This type of evaluation (PBL - Project Based Learning) started to be implemented in 2010/11 in FEUP in the Specialization Course in Design and Product Development and in the future Masters' Program with the same name [6].

Panthalookaran and Binu [7], in Rajagiri School of Engineering and Technology, India, also tried something similar to nurture general management skills in their engineering students. Kostal, Mudrikova and Caganova [8], in Slovak University of Technology, Slovak Republic, improved their teaching methodologies through virtual laboratories, enforcing students' capacities to learn by their self-activity and self-responsibility and improving their communication skills. Martinez, Romero, Marquez and Perez [9] in Polytechnic University of Madrid promoted the PBL in their Mechanical/Industrial Engineering courses. Frank, Lavy and Elata [10], in Technion, Israel, implemented the PBL through mini-projects that require the design and construction of devices that perform predefined tasks.

All these different PBL methodologies are focused on a higher students' responsibility and have a more experimental character with projects to produce or operate specific devices. Although we also have experimental work, a large emphasis is placed on searching scientific data and capacities to clear present ideas and participate in debates.

\section{Methodology}

\section{A. Course Goals}

By the end of the semester, students are expected to have acquired basic and advanced knowledge in the field of ceramic materials, polymers and composites of polymeric matrix, namely:

- Knowledge of the different ceramic materials, polymers and composites of polymeric matrix used in different branches of engineering, their main applications and properties;

- Comprehension about the mechanical properties of these materials;
- Capacities to perform different types of experimental work, collect data, interpret and relate them to the different subjects covered. Perform small projects involving the materials taught; namely materials and manufacturing processes selection;

- Capacities to collect scientific data using different sources (books, scientific papers, databases, internet, technical visits and public oral discussions);

- Capacity to perform practical group works and presentation and discussion of the results achieved.

The ceramics part of the course should contribute to the following CDIO (Conceive-Design-Implement-Operate) skills number [2]:

- 1.2 (nuclear knowledge in engineering);

- 1.3 (advanced knowledge in engineering);

- 2.1 (thinking and resolution of engineering problems);

- 2.2 (experimentation and knowledge discovering);

- 2.4 (personal skills and attitudes);

- 3.1 (group work);

- 3.2 (communication);

- 4.4 (project).

Presently the new evaluation system of engineering courses is based on EUR-ACE skills [11] which for this course are (summary):

- 3.1 - Knowledge and understanding - An in-depth knowledge and understanding of the principles of their branch of engineering;

- 3.2 - Engineering analysis - The ability to solve problems that are unfamiliar, incompletely defined, and have competing specifications;

- 3.3 - Engineering design - An ability to use their engineering judgment to work with complexity, technical uncertainty and incomplete information;

- 3.4 - Investigations - The ability to identify, locate and obtain required data;

- 3.6 - Transferable skills - Work and communicate effectively in national and international contexts.

In this paper emphasis is given to the Practical Work number 1 "Analysis and discussion of a scientific paper", which corresponds to $45 \%$ of the final grade of ceramics part of the course $(45 \%$ for the second work and $10 \%$ for handouts). The following sections describe the objectives of this experimental work, all the tasks done by the students and the evaluation procedure.

Considering the experience obtained in 2009/10 (see reference [12]) with this practical work and students and public presentations recommendations [13], the authors introduced in 2010/11 three innovations:

1) One class (2h) in information literacy in FEUP library about how to use bibliographic databases. This session included competences in searching in scientific databases (compendex, inspect, etc.), integral text, ebooks, patents, dissertation and thesis and how to use the Endnote. This specific competence proved to be very helpful for all students, shortening their searching time and obtaining more valuable information and using it on the reports, as will be demonstrated with the improvement in this year final grades; 
2) Seminar of electronic microscopy given by the Materials Centre of University of Porto (www.cemup.up.pt), in order to give the students specific tools for microstructure analysis of ceramics;

3) Introduction and use of CES 2010 EDUPACK software from Granta [14]. This software is very important to search information about materials and manufacturing processes and to relate ceramic properties with the specific processes for this materials family.

\section{B. Specifications of the Work}

Objective. Analysis, interpretation of a supplied scientific paper about ceramic materials and complementary search about the topic developed on the paper and elaboration of a report, a poster (A4), a presentation and public debate about the performed work.

The main challenge proposed to the students is to do a report that contains the necessary information for the reader to take a decision: "Consider that you are an employee in a company and that your boss asks you to study a subject and supply him with a report containing all the necessary state of art information to take a decision about adopting or modifying a technology/process in the company".

Recommendations: The reports should be quickly understood by the reader. Therefore they should:

- Be well presented (the subjects being well organized enhancing what is more important);

- Be well written and not contain spelling mistakes;

- Present the subjects obeying a scheme defined at the beginning. Thus, after the cover sheet, they should include the index showing the organization of the report;

- Use frequently graphics, tables, figures or others that make the presentation appealing, easy to read and to comprehend the work performed;

- Indicate the main conclusions at the end;

- Identify the references, by names and dates, or numbers, on the text, figures, tables and graphics;

- Use SI Units.

The presentation of samples or parts/components of the studied materials, during the oral presentation, as well as personal initiatives to visit companies or interviews to specialists, related with the proposed topic will be graded positively.

Evaluation. All the groups should deliver the report till the deadline and supply on the 1st day of the oral presentations and debate a CD containing the following elements:

- Presentation of the work;

- Poster;

- Report;

- Elements collected during visits or others.

Not obeying the deadline to deliver all the work elements will be negatively classified. All the reports presented by the students that contain parts from other reports will be graded with " 0 ".

The single use of internet sites as references will be classified very negatively. All the groups have to present in Annex at least the two best scientific papers (copies) found about the studied topic (Warning: these papers should be used as references on the report). Do not forget that there are in the FEUP library, DataBases, such as Compendex and the knowledge library: http://www.bon.pt, where numerous papers can be found.

Reports structure: The basic structure of the reports (to be adapted for each particular paper) should be the following:

Cover sheet: Authors of the report (complete names), local, period of the work and due date, subject and course, work title, number of the group and class, reference to supervisors and main collaborators.

Contents: Include page numbers and all the titles indicated along the work.

Summary and Objectives: The objectives and working methods employed should be clearly indicated.

State of Art: Comprehension and discussion of the following aspects (adapted according to each paper subject and relations with the contents of the curricular unit):

- Typical chemical composition, type of chemical bonds, structure, etc.;

- Powder manufacturing processes;

- Physical and mechanical properties, or others;

- Processing (manufacturing processes for parts and components);

- Applications (practical examples in different areas);

- Future and new challenges;

- Other elements that seem interesting (for instance, recycling possibilities);

Conclusions: Present the main conclusions in a clear synthetic way.

Future work suggested and criticisms: When justified, the difficulties found and suggestions concerning performing future work, working methods, topics, etc., should be indicated.

References: The incorrect indication of the references penalizes significantly the work. Each reference or paper should be indicated in brackets along the text, using the last name of the first author and publication date, or alternatively by a number. At the end of the work, each author cited will have the complete specification of the reference, including:

Author(s); title; editor (or journal where the article is included), data, local of edition and pages.

In case the reference was done by two or more authors the abbreviation et al. can be used in the text, but at the end all the authors have to be referred.

Example:

Reference during the text:

(Duarte et al., 2008) or [1]

Reference in the bibliographic references:

[Duarte et al., 1998] Teresa P. Duarte, Rui J. Neto, Rui Félix, F. Jorge Lino, "Optimization of Ceramic Shells for Contact with Reactive Alloys", Trans Tech Publications, pp. 157-161 (2008);

or

[1] Teresa P. Duarte, Rui J. Neto, Rui Félix, F. Jorge Lino, "Optimization of Ceramic Shells for Contact with 
Reactive Alloys", Trans Tech Publications, pp. 157-161 (2008).

Presentation and Oral Debate: The oral presentation of the work is defined at the beginning of the semester. The maximum time for the presentation is 8 minutes for each group (exceeding this time has a penalty) followed by a debate (around one hour) with all the students that did the same work (see Fig. 1).

This type of evaluation is also implemented in a course (MAT 408 - Transformations in Materials) in the Department of Materials Science and Engineering of Lehigh University, PA, USA, however it is just for a specific part of the course and the theme is always the same, "Bain Debate" (deals with bainite transformation in steels).

The evaluation of each group element is based on the following:

- Time used during the presentation;

- Presentation structure;

- Knowledge of the subject, capacity of making a presentation and answering questions about it.

The questions of other group colleagues and the teaching staff are helpful to enhance the debate. The performance of each student will be evaluated by the teachers of the curricular unit and by the students.

Poster: The poster is evaluated considering the inclusion of the following elements:

- Design;

- Subject title;

- Course;

- Year;

- Objectives;

- Introduction;

- Work done;

- Conclusions;

- Future work;

- Photo of the groups elements;

- Place of the work;

- Other elements considered relevant.

Grade: The final grade is obtained by the evaluation of three main points:

1. Report $(11 / 20)$ :
a) Cover sheet (1/11);
b) Contents (0.5/11);
c) Summary and objectives $(0.5 / 11)$;
d) State of Art (4/11);
e) Conclusions (1/11);
f) Future, criticisms and annex $(0.5 / 11)$;
g) References (1/11);
h) The two best scientific papers and their use on the report $(2 / 11)$
i) Design of the report $(0.5 / 11)$;

2. Poster $(3 / 20)$

3. Oral presentation and debate $(6 / 20)$ :

a) Oral presentation $(3 / 20)$;

b) Debate $(3 / 20)$.

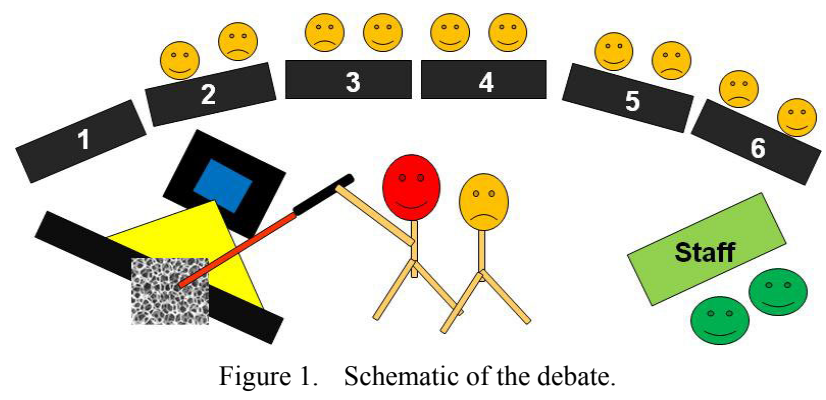

III. CASE STUDY

In the academic year of $2010 / 11$, the following papers were given to the groups:

1. Yoshio Sakka, Fengqiu Tang, Hiroshi Fudouzi, Tetsuo Uchikoshi, "Fabrication of porous ceramics with controlled pore size by colloidal processing", Science and Technology of Advanced Materials 6, 915-920 (2005).

2. Karn Serivalsatit, Baris Kokuoz, Basak YazganKokuoz, Marian Kennedy, and John Ballato, "Synthesis, Processing, and Properties of SubmicrometerGrained Highly Transparent Yttria Ceramics", J. Am. Ceram. Soc., 93 [5] 1320-1325 (2010).

3. Fawad Inam, Haixue Yan, Ton Peijs, Michael J. Reece, "The sintering and grain growth behaviour of ceramic-carbon nanotube nanocomposites", Composites Science and Technology 70, 947-952 (2010).

4. H. K. Lee, S. Zerbetto, P. Colombo, C.G. Pantano, "Glass-ceramics and composites containing aluminum borate whiskers", Ceramics International 36, 1589-1596 (2010).

5. V. S. Kiselov, P. M. Lytvyn, V. O. Yukhymchuk, A. E. Belyaev, and S. A. Vitusevich, "Synthesis and properties of porous SiC ceramics", Journal of Applied Physics 107, 093510, 1-6 (2010).

6. J. Chevalier, L. Gremillard, "Ceramics for medical applications: A picture for the next 20 years", Journal of the European Ceramic Society 29, 1245-1255 (2009).

7. Maria Vallet-Regí, "Ceramics for medical applications”, J. Chem. Soc., Dalton Trans., 97-108 (2001).

8. HaihuaWu, Dichen Li, Yiping Tang, Bo Sun, Dongyang Xu, "Rapid fabrication of alumina-based ceramic cores for gas turbine blades by stereolithography and gelcasting", Journal of Materials Processing Technology 209, 5886-5891 (2009).

9. Y.I. Oka, H. Miyata, "Erosion behaviour of ceramic bulk and coating materials caused by water droplet impingement", Wear 267, 1804-1810 (2009).

10. A. P. Garshin, "Boron and Silicon Nitrides as Mechanical Engineering Ceramics", Refractories and Industrial Ceramics, 50 [5] (2009).

11. V. S. Bakunov and E. S. Lukin, "Particulars of the Technology of High-Density Technical Ceramics. Crystal Growth During Sintering", Glass and Ceramics, 65 [7-8] 263-269 (2008).

12. E. S. Lukin, N. A. Makarov, A. I. Kozlov, N. A. Popova, E. V. Anufrieva, M. A. Vartanyan, I. A. Kozlov, M. N. Safina, D. O. Lemeshev, E. I. Gorelik, and V. S. Bakunov, "Nanopowders for Preparing a New Generation of Oxide Ceramics", Re- 
fractories and Industrial Ceramics, 50 [6] 425-430 (2009).

As an example we select the paper number 11 , by $V$. $S$. Bakunov and E. S. Lukin, "Particulars of the Technology of High-Density Technical Ceramics. Crystal Growth During Sintering”, Glass and Ceramics, 65 [7-8] 263269 (2008).

This paper has the following abstract:

"Growth of the crystals which compose a ceramic is observed at the final stage of sintering or during use at high temperatures. This is due to surface tension forces (in the present case boundary tension) as a result of diffusion or cooperative mass transfer (shear; rotation)".

Students designed posters in accordance with the supplied instructions. Fig. 2 shows two posters of this subject; poster a) is considered a good one, while poster b) had a lower grade (it does not have the period of the work, course, objectives and conclusions, it does not explain the topic of the paper, it does not contain captions and has a poor design).

The analysis of the reports delivered by the students has shown that they can produce a very well structured report, with very high graphical quality (cover sheet, figures and tables, typing font and layout of the pages). This means that in general the reports are pleasant to read and the main conclusions and important data are very easily and quickly obtained.

The weak points detected in the reports are:

1. Many students still have difficulties in indicating the sources of the data, figures and tables used on the report, although very precise instructions were supplied to them (this has been improving over the years);

2. Some did not understand the correct way to indicate the references along the text although they introduce the references at the end in a correct and complete way;

3. There is still a tendency to use as references, a considerable number of websites. Although this is not bad, because a lot of useful information can be obtained, it is not enough for engineering students;

4. They find more important and detailed information, related with the subjects taught on the course, when they analyse scientific papers, although many of them tend to search more publications just by the authors of the paper under study;

5. The great majority selected the two papers that they considered the most important and included them in the Annex, but they did not use the concepts/ideas contained in the papers in the report. This means that this capacity to extract the most important data (synthesis capacity) from a subject that is studied and explained in detail is still a lack in students' capacities. Some of them complain about the difficulties in understanding technical English;

6. Most of the students focus some innovative tendencies for the future, but many of them forget to check if the authors have published any other papers after the current one. This is a very important issue, considering that not all the papers submitted to the groups were from the same year, and many innovations could occur after the paper publishing date;

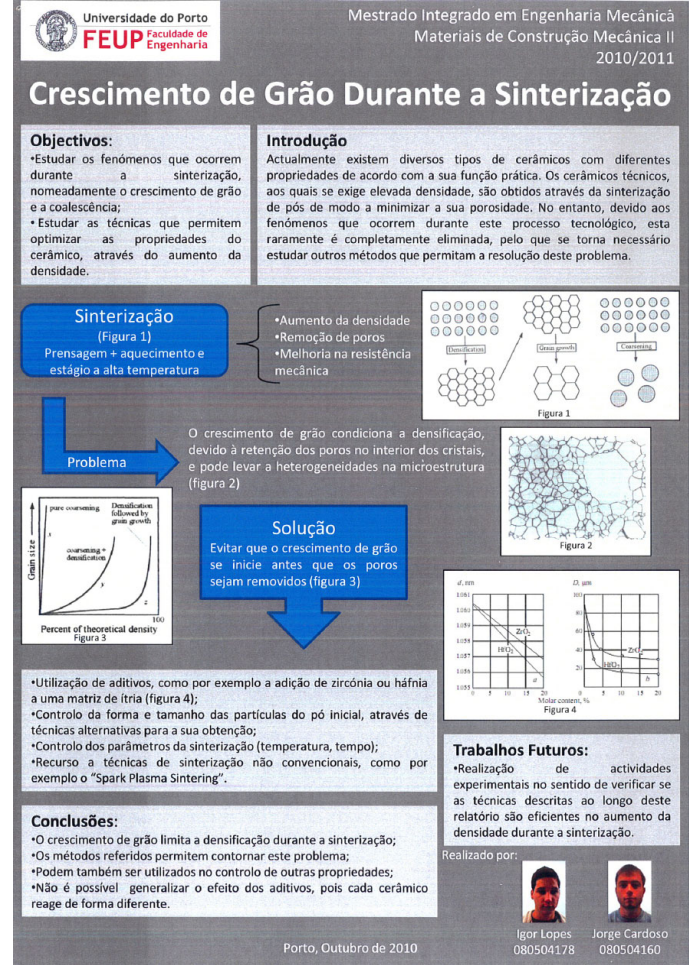

a)

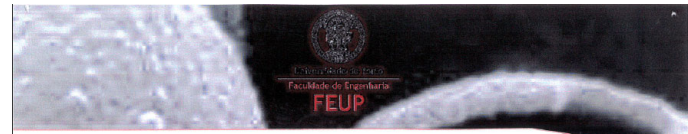

Cerâmicos Tradicionais e Técnicos

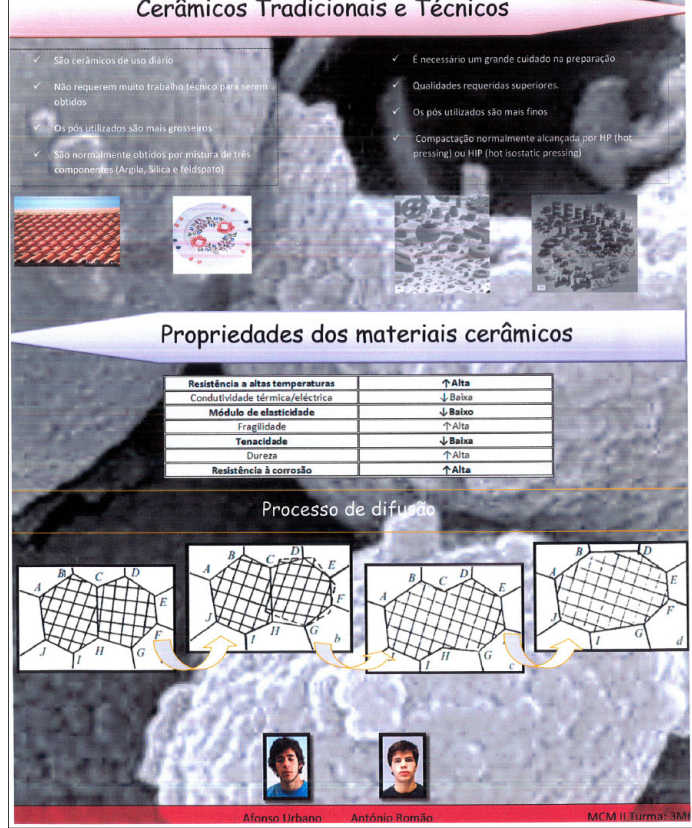

b)

Figure 2. Posters of the work; a) poster with a good grade and b) poster with lower final grade.

7. In the specific case of the paper "Particulars of the Technology of High-Density Technical Ceramics. Crystal Growth During Sintering", it was detected that the relation between the densification and grain growth is well understood and that to completely reduce the final porosity, located on triple points, some resistance is lost due to the fast grain growth. However students still have some difficulties in 
relating this sintering behaviour with the manufacturing processes and type of parts to be obtained;

8. Some students present some microstructures but they have difficulties in relating their influence on the grain growth kinetics.

9. The effect of the additives on the grain growth kinetics is only slightly touched.

\section{RESULTS}

From the work performed by the students, one can summarize the following points:

- Some difficulties still persist to transmit to the students groups the rigor of the assignment and their responsibility in creating the necessary conditions to independently conduct the work to reach the course goals.

- Students are still not very comfortable with this type of classes, and many of them tend to almost not raise questions to the colleagues, because they fill inhibited and are afraid of what the colleagues can think about them;

- Some students are very active and participate intensively, but many times they just talk about generalities, when the teaching staff ask about more detailed aspects of the work, and specially topics where it is necessary to relate the things that they read with the contents of the course, they have serious difficulties;

- Although students have to evaluate other students' presentations and discussions, they tend to give very high grades to all of them and not distinguish the ones that really know the subject of the curricular unit. However, this year they started to be a little more rigorous;

- This is the third year of implementation of this type of work, and we figure out that students are improving (and also are the grades) and start to be more familiar with this type of classes. This is the only class, during their Integrated Master's Course in Mechanical Engineering, where they are confronted with this type of continuous evaluation.

- We asked some students to give their opinion about this practical work, and the main points can be summarized as:

- Difficulties in reading and understanding technical English, but in the end they considered that they improved a lot. This is the main difficulty and we are strongly convinced that this is the reason why they do not include more scientific papers information on the reports;

- Short period of time to perform the work, considering the requests that they had at the same time for other courses;

- Difficulties in collecting information about more technical aspects, due to not finding the correct papers and also because some of the papers that they considered interesting, based on the available abstracts, were not of free access;

- Not many books available about ceramics;

- They liked the challenge for the deep study of the ceramic topics, considered the supplied papers interest- ing, learned a lot and should even have more time to better study the subject;

- The work contributed to their synthesis capacity, and a systematic way to study a subject.

Fig. 3 shows the percentage of approved students since the academic year of 2005/06 until the present.

The graph reveals that the change from the classic grading (done with the theoretical classical exam 2005/2006) to the present one (started in 2006/2007) improved the motivation for the curricular unit, resulting in a larger number of approved students (we are just considering the students that were submitted to all the evaluation procedure).

It should be also referred that the slight decrease in the year of $2009 / 10$ is due to the fact that a more rigorous control of classes' participation and assiduity gave us the capacity to distinguish students. In 2010/11 the number of approved students increased again because students know already that we are extremely rigorous in controlling all the evaluation phases (for instance a student that misses one class where a part of the work is done has " 0 " value for that specific part).

Fig. 4 shows the average final grade. This graph also presents an improvement on the average grades in the last four academic years. We are convinced that the value obtained in $2010 / 11$ is due to the clear rules of how the curricular unit works and the specific classes that they had in information literacy, electronic microscopy analysis and how to use the software for materials and processes selection (CES EDUPACK 2010).

\section{\% Approved Students}

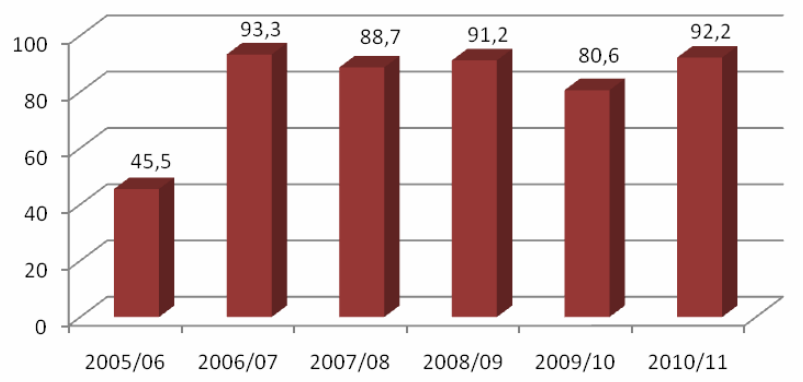

Figure 3. Percentage of approved students along the last 5 academic years.

\section{Average classification}

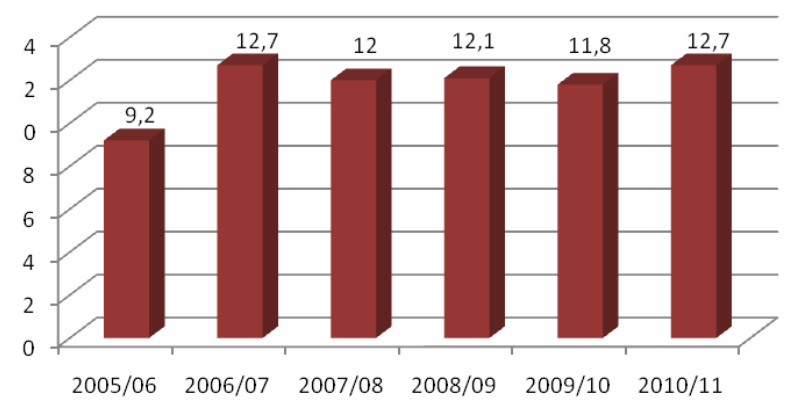

Figure 4. Average classification (out of 20) along the last five academic years. 


\section{CONCLUSIONS}

The introduction of continuous evaluation in the course of Materials II of the Integrated Masters in Mechanical Engineering of Faculty of Engineering of University of Porto, changed, with success, the way students study the ceramics materials subject.

It was demonstrated that the evaluation of the students with a practical work that demands a considerable search in the World Wide Web and scientific databases, followed by the elaboration of a report and a public debate is a very demanding work that they enjoy and actively participating. This structure facilitates their learning and enrolment, increasing their knowledge about the ceramic topics covered on the course and contributes to the improvement of their research and synthesis capacities which they will constantly need in the near future.

Ideally, this experience and results obtained should encourage other professors to try something similar.

\section{ACKNOWLEDGMENT}

We would like to acknowledge the students of the third year of MIEM (2009/10) Cristiano Coutinho, Pedro Marques, Ana Tavares, José Vilas, Albertino Arteiro and Nuno Santos, and (2010/11) Jorge Cardoso and Fernando Pimenta for their important feedback about the course.

\section{REFERENCES}

[1] K. Henning, G. Bornefeld, and S. Brall, "Mechanical engineering at RWTH Aachen University: professional curriculum development and teacher training”, Europ. J. Eng. Education, vol. 32 (4), pp. 387-399, 2007. doi:10.1080/03043790701333584

[2] http://www.cdio.org, accessed December 2010.

[3] http://www.fe.up.pt/si uk/disciplinas geral.FormView?P CAD C ODIGO=EM0027\&P_ANO_LECTIVO=2009/2010\&P_PERIOD $\mathrm{O}=1 \mathrm{~S}$, accessed December 2010.

[4] M. Harmer, H. Chan, and G. Miller, "Unique opportunities for microstructural engineering with duplex and laminar composites", J. Am. Ceram. Soc., 75 (7), pp. 1715-1728, 1992. doi:10.1111/ j.1151-2916.1992.tb07188.x
[5] http://ec.europa.eu/education/lifelong-learningpolicy/doc48 en.htm, accessed December 2010.

[6] C. Aguiar, and X. Carvalho,. "Design e desenvolvimento de produto: aprendizagem baseada em projectos (PBL Project Based Learning)", Tecnometal [188], pp. 26-32, Maio Junho 2010 (in portuguese)

[7] V. Panthalookaran and R. Binu, "Some models and methods to nurture general management skills in engineering studets living in large residential communities", ESDA 2010 - ASME 2010 10th Biennial Conference on Engineering Systems Design and Analysis, session on Science, Engineering and Education, Istanbul, Turkey, July 12-14, 2010.

[8] P. Kostal, A. Mudrikova and D. Caganova, "The virtual laboratory of program control", ESDA 2010 - ASME 2010 10th Biennial Conference on Engineering Systems Design and Analysis, session on Science, Engineering and Education, Istanbul, Turkey, July 1214, 2010.

[9] M. Martinez, G. Romero, J. Marquez, and J. Perez, "Integrating teams in multidisciplinary project based learning in mechanical engineering", IEEE EDUCON Engineering 2010 - The Future of Global Learning Engineering Education, April 14-16, Madrid, Spain, 2010.

[10] M. Frank, I. Lavy, and D. Elata, "Implementing the project -based learning approach in an academic engineering course", Int. J. Techn. Design Educ. [13], pp. 273-288, 2003.

[11] http://www.engc.org.uk/education--skills/accreditation/europeanaccreditation.aspx, accessed December 2010.

[12] F.J. Lino, and T. Duarte, "Development of competitive skills in future mechanical engineers", ESDA 2010 - ASME 2010 10th Biennial Conference on Engineering Systems Design and Analysis, session on Science, Engineering and Education, Istanbul, Turkey, July 12-14, 2010.

[13] F.J. Lino, and T. Duarte, "EM0027 Materiais de construção mecânica II", Jornada de Partilha Pedagógica, Laboratório de Ensino e Aprendizagem (LEA), FEUP, 14 de Julho de 2010 (in portuguese).

[14] http://www.grantadesign.com, accessed November 2010.

\section{AUTHORS}

F. Jorge Lino and Teresa P. Duarte are with Universidade do Porto, Porto, Portugal.

Received April 5th, 2011. Published as resubmitted by the authors April 20th, 2011. 